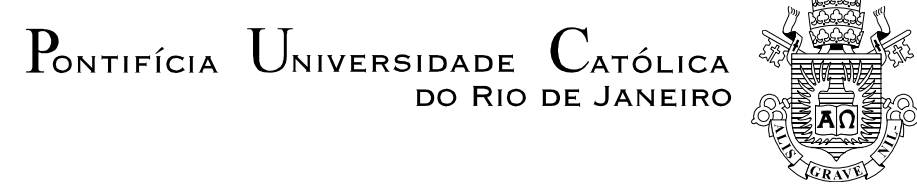

Luciano Vereda Oliveira

Suavização do Preço das Commodities e Estabilização Macroeconômica

Tese de Doutorado

Tese apresentada como requisito parcial para obtenção do título de Doutor pelo Programa de PósGraduação em Economia da PUC-Rio.

Orientador: Prof. Eduardo Loyo

Rio de Janeiro, agosto de 2004 


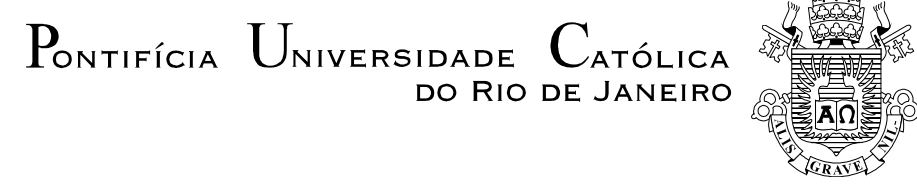

Luciano Vereda Oliveira

\title{
Suavização do Preço das Commodities e Estabilização \\ Macroeconômica
}

Tese apresentada como requisito parcial para obtenção do título de Doutor pelo Programa de Pós-Graduação em Economia da PUC-Rio. Aprovada pela Comissão Examinadora abaixo assinada.

\author{
Prof. Eduardo Loyo \\ Orientador \\ PUC-Rio \\ Prof. Afonso Bevilaqua \\ PUC-Rio \\ Prof. Márcio Garcia \\ PUC-Rio \\ Prof. Afonso Celso Pastore \\ EPGE-FGV \\ Prof. Tiago Cavalcanti \\ UFPE \\ Prof. João Pontes Nogueira
}

Coordenador Setorial do Centro de Ciências Sociais - PUC-Rio 
Todos os direitos reservados. É proibida a reprodução total ou parcial do trabalho sem autorização da universidade, do autor e do orientador.

\section{Luciano Vereda Oliveira}

Graduou-se em Engenharia Elétrica na PUC-Rio em 1990. Atuou em diversas instituições públicas e privadas em assuntos relacionados às áreas de Economia e Finanças. Ao longo do programa de Doutorado dedicou-se ao estudo de modelos novo-keynesianos com foco em políticas ótimas de estabilização. Atualmente é professor agregado do Departamento de Economia da PUC-Rio e desenvolve pesquisas nas áreas de Macroeconomia, Economia Monetária e Economia Internacional.

Ficha Catalográfica

Oliveira, Luciano Vereda

Suavização do preço das commodities e estabilização macroeconômica / Luciano Vereda Oliveira ; orientador: Eduardo Loyo. - Rio de Janeiro : PUC, Departamento de Economia, 2004.

258 f. : il. ; $30 \mathrm{~cm}$

Tese (doutorado) - Pontifícia Universidade Católica do Rio de Janeiro, Departamento de Economia.

Inclui referências bibliográficas.

1. Economia - Teses. 2. Estabilização macroeconômica. 3. Políticas ótimas de estabilização. 4. Instrumentos auxiliares de estabilização. 5. Intervenção sobre os preços de insumos comerciáveis. 6. Modelos novo-Keynesianos de economia aberta. I. Loyo, Eduardo. II. Pontifícia Universidade Católica do Rio de Janeiro. Departamento de Economia. III. Título. 


\section{Agradecimentos}

Gostaria de registrar o meu agradecimento a todos os professores e colegas do Departamento de Economia da PUC-Rio, pelos ensinamentos e pelas discussões que tanto enriqueceram os meus quatro anos e meio de curso.

Ao professor Eduardo Loyo dedico um agradecimento especial pela sua amizade, por sua orientação mais que perfeita e pelas inúmeras lições de Macroeconomia que recebi ao longo de nosso convívio.

Aos professores membros da banca pela leitura minuciosa, pelas críticas e comentários.

À CAPES e à FAPERJ pelo suporte financeiro durante o doutorado.

Aos meus saudosos pais Helena e Valentim que, embora distantes, estão sempre presentes no meu coração, e ao meu irmão Álvaro.

À minha esposa Alessandra, pelo amor e dedicação. 


\section{Resumo}

Oliveira, Luciano Vereda. Suavização do Preço das Commodities e Estabilização Macroeconômica . Rio de Janeiro, 2004. 258p. Tese de Doutorado - Departamento de Economia, Pontifícia Universidade Católica do Rio de Janeiro.

O objetivo principal do trabalho é avaliar as vantagens e desvantagens associadas à utilização, no âmbito de uma pequena economia aberta, de um mecanismo de intervenção sobre variações dos preços relativos domésticos de insumos intermediários comerciáveis. Esse mecanismo pode ser implementado por meio de uma combinação de tributos e subsídios às importações e exportações dos insumos comerciáveis, com alíquotas variáveis ao longo do tempo. Tal intervenção assume o papel de um instrumento auxiliar de estabilização que, ao ser manejado de forma coordenada com a taxa de juros nominal e os demais instrumentos convencionais de política monetária, pode vir a melhorar a resposta da economia aos choques que a atingem. Um exemplo concreto desse tipo de mecanismo é a CIDE (Contribuição de Intervenção sobre o Domínio Econômico), que tinha entre seus intuitos originais impedir que a volatilidade do preço do petróleo no mercado internacional se transmitisse integralmente aos preços domésticos dos derivados. O trabalho, portanto, destina-se a analisar e responder as seguintes questões: (i) determinar as circunstâncias nas quais a intervenção sobre os preços internacionais dos insumos pode se somar à manipulação da taxa de juros nominal na tentativa de melhor estabilizar a economia; (ii) investigar a natureza da intervenção ótima, ou seja, como o instrumento auxiliar e a taxa de juros nominal devem se movimentar conjuntamente em resposta aos choques; e (iii) medir os ganhos de bem estar que advêm da disponibilidade desse instrumento auxiliar de estabilização.

\section{Palavras-chave}

Estabilização Macroeconômica; Políticas Ótimas de Estabilização; Instrumentos Auxiliares de Estabilização; Intervenção sobre os Preços de Insumos Comerciáveis; Modelos Novo-Keynesianos de Economia Aberta. 


\section{Abstract}

Oliveira, Luciano Vereda. Commodity Price Smoothing and Macroeconomic Stabilization. Rio de Janeiro, 2004. 258p. PhD. Thesis Departamento de Economia, Pontifícia Universidade Católica do Rio de Janeiro.

The main purpose of the current work is to evaluate the advantages and disadvantages of using a mechanism which intervenes in domestic relative prices of tradable intermediate goods. Such a mechanism can be implemented by a combination of taxes and subsidies to imports and exports of tradable intermediate goods, with rates that vary over time. This intervention performs as an auxiliary stabilization instrument that is managed in a coordinated fashion with more conventional ones, such as the nominal interest rate. In the end this work will look into the matters of (i) investigating the circumstances under which the intervention in international commodity prices, together with the nominal interest rate, might help in the task of stabilizing the economy; (ii) determining the optimal response of the available instruments to the shocks that hit the economy; and (iii) measuring the welfare consequences of the availability of this auxiliary stabilization instrument.

\section{Palavras-chave}

Macroeconomic Stabilization; Optimal Stabilization Policies; Auxiliary Stabilization Instruments; Intervention in Intermediate Goods Prices; NewKeynesian Open Economy Models. 


\section{Sumário}

1 Introdução 14

$\begin{array}{ll}\text { 1.1. Metodologia } & 18\end{array}$

1.2. Plano de Trabalho 20

2 Modelo Estático 23

2.1. Descrição da Economia 23

2.2. Equilíbrio com Preços Flexíveis 27

2.3. Equilíbrio na presença de rigidez nominal de preços 38

2.4. Derivação da medida de bem estar 48

2.5. Determinação da política de estabilização ótima 50

2.6. Resultados na presença de choques ineficientes 53

2.7. Intervenção governamental sobre os preços relativos dos insumos 60

2.8. Comentários acerca do comportamento das variáveis $\begin{array}{ll}\text { nominais } & 64\end{array}$

3 Modelo Dinâmico 68

3.1. Descrição da economia 68

3.2. Equilíbrio com preços flexíveis $\quad 71$

3.3. Equilíbrio na presença de rigidez nominal de preços 74

3.4. Derivação da medida de bem estar $\quad 81$

4 Determinação das políticas de estabilização ótimas 91

4.1. Trajetórias ótimas com livre ajuste da taxa de juros nominal 93

4.1.1. Formulação do problema 93

4.1.2. Resultados 98

4.2. Obstáculos ao manejo da taxa de juros nominal 106

4.2.1. Formulação do problema 107

4.2.2. Resultados 110

4.3. Ocorrência de choques ineficientes 125 
4.3.1. Nova estrutura da economia 125

4.3.2. Formulação do problema 130

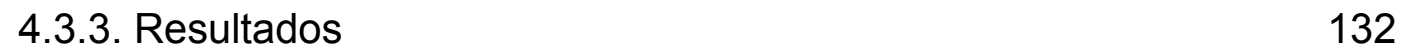

4.4. Choque ineficiente oriundo de variações nos gastos $\begin{array}{ll}\text { primários } & 145\end{array}$

4.4.1. Nova estrutura da economia 145

4.4.2. Formulação do problema 146

$\begin{array}{ll}\text { 4.4.3. Resultados } & 149\end{array}$

4.5. Choque ineficiente oriundo de variações no serviço da dívida $\begin{array}{ll}\text { do Governo } & 160\end{array}$

$\begin{array}{ll}\text { 4.5.1. Nova estrutura da economia } & 160\end{array}$

4.5.2. Formulação do problema 162

$\begin{array}{lr}\text { 4.5.3. Resultados } & 164\end{array}$

$\begin{array}{ll}5 \text { Conclusão } & 176\end{array}$

6 Referências bibliográficas $\quad 185$

7 Apêndices 189

7.1. Especialização na produção de insumos intermediários 189

7.2. Efeitos de bem estar provocados por mudanças no grau de afastamento do livre comércio 190

7.3. Solução do sistema formado pelas equações (2-44) a (2-48) 197

7.4. Solução do sistema formado pelas equações (2-80) a (2-86) 198

7.5. Aproximação de $2^{a}$ ordem da função de bem estar do agente representativo 201

7.6. Aproximação de $2^{a}$ ordem da expressão para a medida de dispersão de preços relativos 207

7.7. Análise da influência dos choques básicos sobre a taxa de $\begin{array}{ll}\text { juros natural } & 210\end{array}$

7.8. Derivação da curva de Phillips 212

7.9. Derivação das curvas de Phillips sub-setoriais 226

7.10. Derivação da medida de bem estar 229

7.11. Simplificação da expressão para $L_{t}$ 
7.12. Cálculo da aproximação de $1^{a}$ ordem da identidade orçamentária do Governo

7.13. Obtenção dos sistemas que caracterizam as trajetórias ótimas das variáveis endógenas do modelo

7.14. Alguns comentários sobre as regras ótimas de política monetária discutidas na Seção 4 


\section{Lista de figuras}

Figura 1: Comportamento ótimo da taxa de juros nominal quando o instrumento auxiliar está disponível.

Figura 2: Comportamento ótimo da inflação quando o instrumento auxiliar está disponível.

Figura 3: Comportamento ótimo do hiato do produto quando o instrumento auxiliar está disponível.

Figura 4: Comportamento ótimo do preço relativo do sub-setor $A$ de SBC quando o instrumento auxiliar está disponível.

Figura 5: Comportamento ótimo do instrumento auxiliar.

Figura 6: Comportamento ótimo das taxas de juros nominal e natural na presença de obstáculos ao ajuste da taxa de juros nominal.

Figura 7: Comportamento ótimo da inflação na presença de obstáculos ao ajuste da taxa de juros nominal.

Figura 8: Comportamento ótimo do hiato do produto na presença de obstáculos ao ajuste da taxa de juros nominal.

Figura 9: Comportamento ótimo da diferença entre as taxas de juros real ex-ante e natural na presença de obstáculos ao ajuste da taxa de juros nominal.

Figura 10: Comportamento ótimo do preço relativo do sub-setor $A$ de SBC na presença de obstáculos ao ajuste da taxa de juros nominal.

Figura 11: Comportamento ótimo do instrumento auxiliar de estabilização na presença de obstáculos ao ajuste da taxa de juros nominal.

Figura 12: Comportamento ótimo da taxa de juros nominal e comparação com a trajetória seguida pela taxa de juros natural caso a economia seja atingida por um choque tributário exógeno.

Figura 13: Comportamento ótimo da inflação na presença de um choque tributário exógeno. 
Figura 14: Comportamento ótimo do hiato do produto na presença de um choque tributário exógeno.

Figura 15: Comportamento ótimo da diferença entre as taxas de juros real ex-ante e natural na presença de um choque tributário exógeno.

Figura 16: Comportamento ótimo do preço relativo do sub-setor $A$ de SBC na presença de um choque tributário exógeno.

Figura 17: Comportamento ótimo do instrumento auxiliar de estabilização na presença de um choque tributário exógeno.

Figura 18: Choque ineficiente oriundo de um choque tributário exógeno e choque ineficiente "líquido" construído a partir do ajuste ótimo do instrumento auxiliar.

Figura 19: Comportamento ótimo da taxa de juros nominal e comparação com a trajetória seguida pela taxa de juros natural (choque ineficiente oriundo de variações nos gastos primários).

Figura 20: Comportamento ótimo da inflação na presença de um choque ineficiente oriundo de variações nos gastos primários.

Figura 21: Comportamento ótimo do hiato do produto na presença de um choque ineficiente oriundo de variações nos gastos primários.

Figura 22: Comportamento ótimo da diferença entre as taxas de juros real ex-ante e natural na presença de um choque ineficiente oriundo de variações nos gastos primários.

Figura 23: Comportamento ótimo do preço relativo do sub-setor $A$ de SBC na presença de um choque ineficiente oriundo de variações nos gastos primários.

Figura 24: Comportamento ótimo do instrumento auxiliar de estabilização na presença de um choque ineficiente oriundo de variações nos gastos primérios.

Figura 25: Choque ineficiente oriundo de variações nos gastos primários governamentais e choque ineficiente "líquido".

Figura 26: Comportamento ótimo da taxa de juros nominal e comparação com a trajetória seguida pela taxa de juros natural 
quando a economia é atingida por um choque ineficiente oriundo de variações no serviço da dívida pública.

Figura 27: Comportamento ótimo da inflação na presença de um choque ineficiente oriundo de variações no serviço da dívida pública.

Figura 28: Comportamento ótimo do hiato do produto na presença de um choque ineficiente oriundo de variações no serviço da dívida pública.

Figura 29: Comportamento ótimo da diferença entre as taxas de juros real ex-ante e natural na presença de um choque ineficiente oriundo de variações no serviço da dívida pública.

Figura 30: Comportamento ótimo do preço relativo do sub-setor $A$ de SBC na presença de um choque ineficiente oriundo de variações no serviço da dívida pública.

Figura 31: Comportamento ótimo do instrumento auxiliar de estabilização na presença de um choque ineficiente oriundo de variações no serviço da dívida pública.

Figura 32: Choque ineficiente oriundo de variações no serviço da dívida pública e choque ineficiente "líquido" construído a partir do ajuste ótimo do instrumento alternativo.

Figura 33: Bem estar como função do grau de afastamento do livre comércio.

Figura 34: Bem estar como função do grau de afastamento do livre comércio (caso com subsídios governamentais).

Figura 35: $L^{*} \times \phi_{\pi}\left(\lambda_{i}=4\right)$.

Figura 36: $L^{*} \times \phi_{\pi}\left(\lambda_{i}=8\right)$.

Figura 37: $L^{*} \times \phi_{\pi}\left(\lambda_{i}=16\right)$.

Figura 38: $L^{*} \times \phi_{\pi}\left(\lambda_{i}=32\right)$. 


\section{Lista de tabelas}

Tabela 1: Valores dos parâmetros estruturais.

Tabela 2: Resultados de bem estar na presença de restrições ao ajuste da taxa de juros nominal.

Tabela 3: Diferenças nos resultados de bem estar calculados.

Tabela 4: Estatísticas presentes na expressão para $L^{*}$.

Tabela 5: Resultados de bem estar na presença de choques tributários exógenos.

123

Tabela 6: Diferenças nos resultados de bem estar calculados.

123

Tabela 7: Estatísticas presentes na expressão para $L^{*}$.

Tabela 8: Resultados de bem estar com choques ineficientes oriundos de variações nos gastos primários do Governo.

Tabela 9: Diferenças nos resultados de bem estar calculados.

123

Tabela 10: Estatísticas presentes na expressão para $L^{*}$.

Tabela 11: Resultados de bem estar com choques tributários ineficientes oriundos de variações no serviço da dívida pública.

Tabela 12: Diferenças nos resultados de bem estar calculados.

123

Tabela 13: Estatísticas presentes na expressão para $L^{*}$.

Tabela 14: $\lambda$ ótimo como função de $\varepsilon$.

Tabela 15: $\lambda$ ótimo como função de $\eta$.

Tabela 16: Pesos ótimos para regras de política monetária pertencentes às famílias (4-28) e (4-29) (modelo da seção 4.2).

Tabela 17: Pesos ótimos para regras de política monetária pertencentes às famílias (4-28) e (4-29) (modelo da seção 4.3).

Tabela 18: Pesos ótimos para regras de política monetária pertencentes às famílias (4-28) e (4-29) (modelo da Seção 4.4).

Tabela 19: Pesos ótimos para regras de política monetária pertencentes às famílias (4.28) e (4.29) (modelo da Seção 4.5). 